\title{
Innovating alongside designers
}

\section{Deana McDonagh and Joyce Thomas}

School of Art + Design, Beckman Institute, University of Illinois at Urbana-Champaign

\section{REVIEW}

Please cite this paper as: McDonagh D, Thomas J. Innovating alongside designers. AMJ 2013, 6, 1, 29.-35. http://doi.org/10.21767/AMJ.2013.1586

Corresponding Author:

Professor Joyce Thomas

Visiting Scholar

Beckman Institute for Advanced Science and

Technology

University of Illinois (Urbana.-Champaign)

405 North Mathews Avenue

Urbana, IL 61801 USA

\section{Abstract}

Building alliances with industrial designers offers health innovators a unique pathway to create new modes to serve their patients. Cross-pollination of ideas from the earliest stages of development in interdisciplinary research and development teams including major stakeholders and designers can lead to more meaningful and impactful innovations.

A shift in future healthcare from cure to prevention will rely more heavily upon the individual. The home environment will house consumer medical devices that will carry out basic monitoring of the individual. While technologies are currently being developed to support this trend, there is a gulf that exists between the often-complex interfaces required by the highly specific functionality of products and the emotional needs of the target user. If a target user 'feels' a product was designed 'just for them' they are more likely to develop an emotional bond with that product. This manifests itself in the user engaging and interacting with the product. If a product, regardless of its high functionality, does not resonate with the user, this tends to result in product underuse, misuse and possible abandonment. When those products are related to a course of medical rehabilitation or treatment, these results could be translated to 'more compliant' and 'less compliant' and ultimately can impact upon how a person heals.
Industrial designers focus on ensuring that both the functional and emotional needs of mainstream users as well as technical--expert--users are met. Design research provides the opportunity to bridge the gap between the functional requirements and the less tangible unmet needs of the user by exploring authentic human behaviour.

This paper presents case studies of collaborative, interdisciplinary teams employing human-centred design and empathic research strategies (incorporating shared language, collaboration, ethnography, empathy and empathic modelling) to create real solutions that are responding to real needs of real users.

The future is interdisciplinary. The future is bright.

\section{Key Words}

Human-centred design, research strategies, emotional needs, authentic human behaviour

\section{Introduction: Building alliances with designers}

While engineering concentrates on solving technical and functional problems, industrial design focuses on solving the physical and emotional human needs surrounding those problems. Industrial design offers a critical bridge amongst and between diverse disciplines in the problem finding and problem solving processes, and then helping to transform emerging technologies from the laboratory into real products that benefit users, and decreasing time from concept development to market introduction.

\section{Innovating through design}

Personal health care is emerging as a critical means by which the individual can manage their physical health and wellbeing without totally relying on medical office-.'based visits. This attention to health care does not replace the medical practitioner but rather places the responsibility of basic healthy living upon the individual. Eating a healthy diet and exercising regularly are only one part of the equation. Using home--based medical technology, people can play an active part in safeguarding their personal health. This commonly happens with devices that measure temperature, blood pressure, blood oxygen, glucose and heart pacemakers. These devices generally 
require a person to change their lifestyle to make room/time for the monitoring activities, as well as to make space for the functionally/medically styled devices that stand out in the home environment. In the future, we hope to devise ways for monitoring technology to be merged more ubiquitously into a person's material landscape (e.g. products that people surround themselves with).

In the US, we see an emerging trend towards integrating health monitoring into devices whose primary use was related to entertainment. The collaborations between Nike and Apple led to the 'Nike + iPod' that encourages users to exercise accompanied by their favourite tunes. The 'Wii Fit' was an innovative disruption in the video game industry when it introduced a controller that encouraged exercise both for the individual and group activities. Other examples include 'Fit Bit' - a discreet device that monitors an individual's daily travel, exercise and sleep. It also integrates with other user-inputed data including food consumption, heart rate, blood pressure, and glucose to help users understand the impact of their activity towards healthy living. These products represent an emerging market where technology fits nearly seamlessly into a person's lifestyle while it monitors their actions and/or health.

With the rising cost of health care, an aging population, people living longer, and an increase in people with disabilities, there is growing emphasis on the individual sharing in the responsibility for their health care ${ }^{1-5}$. Whether it is simply a change in eating and exercise habits, or also playing an active role in the monitoring of the physical health, it is becoming a social, political and economic necessity for people to direct their own personal health care. While the areas of personal medical devices for use in home environments is forecasted to increase considerably, there are few products available on the market that are actually intuitive to use for the mainstream user. When medically relevant products evoke a perception of stigma for the individual (e.g. making them feel that others will see them as broken or weak), they tend to be underused and at worst abandoned ${ }^{6,7}$.

In too many cases, the use of some equipment (e.g. hearing aids) draws undue attention to the individual as being someone 'in need' or 'broken' rather than that equipment appearing to function simply as an extension of the person or even a as fashion statement ${ }^{8,9}$ (e.g. eye glasses). Medical devices can be transformed using empathic design techniques to give these devices a more appropriate design aesthetic that is better suited to the individual's personal image of himself or herself. These products need to fit effortlessly into multiple public and private environments so that they do not draw unwanted attention. More intuitive products present the opportunity for increased compliance ${ }^{10}$ of prescribed usage by the individual.

"Modern technologies are expanding the capabilities of health care, with the resulting great economic opportunities serving as a driving force for innovation." 7

Figure 1: Examples of monitoring devices intended for personal use within the home environment
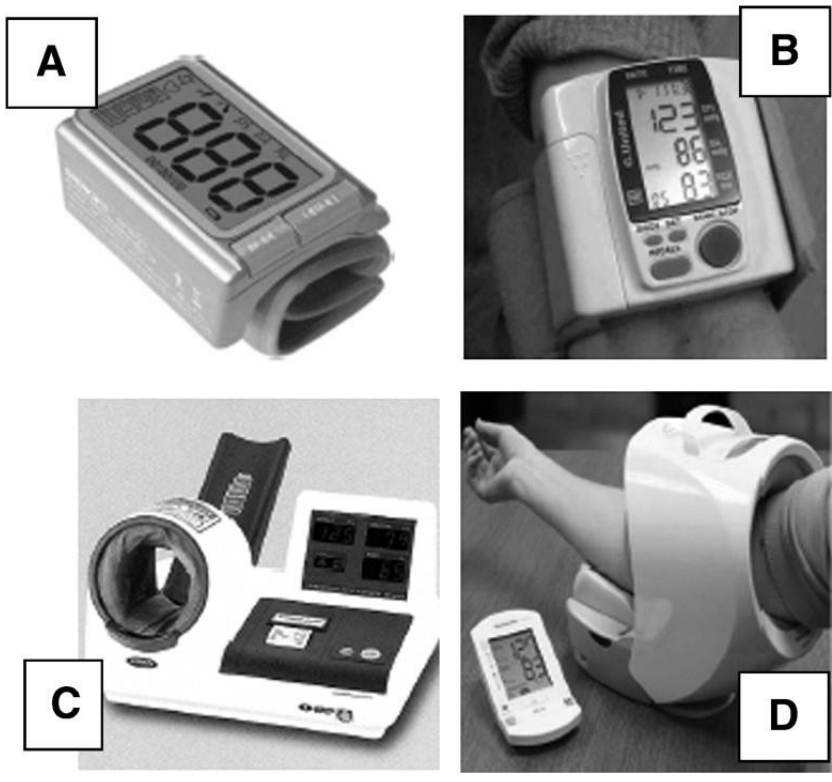

Current medical/health maintenance products in the market place are often stigmatising due to the use of materials, forms and colour. Figure 1 represents a range of blood pressure monitors specifically designed for home use $(A=$ wrist blood pressure monitor, $B=$ portable blood pressure monitor, $C+D=$ fully automated blood pressure machines).

Bitterman ${ }^{1}$ in reviewing this group of products says:

"Even a cursory glance at the models reveals the problems in their visual display, colour selection, bullet size and shape, performance complexity, closeness of elements, and inconsistency in controls and non-intuitive, non--self-explanatory display."

Human-centred empathic design ensures products are highly functional, intuitive to use and effective in completing tasks. Product design can impact upon whether such devices are used, underused or at worst, abandoned by users.

\section{Case Study: Interdisciplinarity + Innovation + Creativity}

Collaboration amongst experts in industrial design, psychology, medicine and bioengineering have enabled the development of a community of researchers and 
scholars at an American university that employ more holistic and empathic design approaches in educational and research projects. This programme has already begun to enrich the student experience and generate unique curricula that build on the synergy of faculty and student capital from diverse disciplines. Employing human-centred design and empathic research strategies (e.g. shared language, collaboration, ethnography, and empathy) ${ }^{11,12,13}$ in both the classroom and research activities has ensured that functional and emotional needs of users (medical professionals and mainstream users) are met ${ }^{14,15}$. Over the course of the programme a holistic design approach is being applied to a sample of conceptual student and faculty research projects. This integration ensures greater opportunity of technology transfer of discrete products developed in scientific laboratories, to human-.-centred, production-ready solutions. ${ }^{16}$

This program supports more effective design outcomes for medical and bioengineering research projects, and it enhances collaborative opportunities in design, psychology, medical informatics, and engineering education.

\section{Portfolio of research projects}

The authors present a portfolio of unique projects supported by a diverse interdisciplinary team of researchers from industrial design (the authors), bioengineering (Stephen Boppart, Ting Lu), medical informatics (Bruce Schatz) and psychology (Brian Ross). This collaboration has attracted graduate and undergraduates students from various disciplines (e.g. general engineering, biology, bioengineering, industrial design, graphic design and business) as researchers and product developers.

All of the student projects presented here employ a similar and iterative design process (e.g. repetition of the process of concept generation, development, refinement, user feedback, and prototype) but vary in duration and depth. Whilst some projects are conceptual, others have more potential for actual production in the near future.

\section{Interdisciplinary research projects}

\section{Bathroom of the future}

Yearlong Capstone Project for bioengineering undergraduate students.

Bioengineering students in their final year of undergraduate study explore means of utilising sensor technologies to ubiquitously monitor personal health data whilst an individual is in their personal (home) bathroom, supported by industrial design professional practitioners (the authors). Emphasis in early brainstorming sessions (refer to Figure 2) was placed on problem finding rather than problem solving.
Figure 2: Bioengineering students brainstorming the 'bathroom of the future'

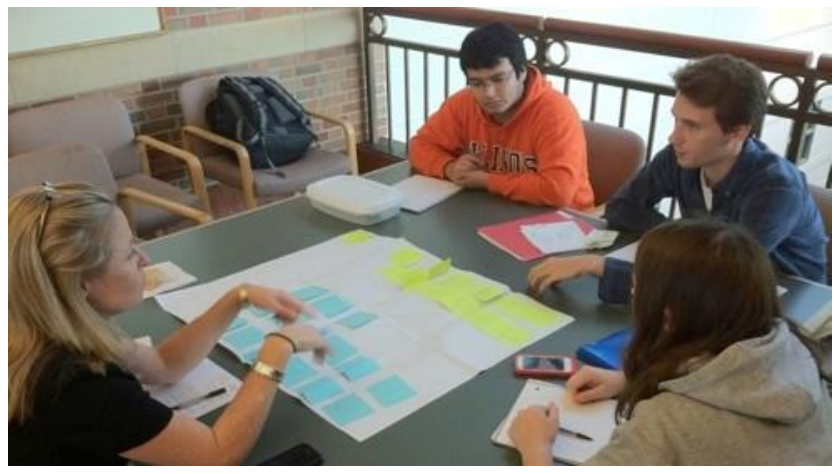

These students were encouraged to explore conceptual ideas through rough sketch modelling techniques. This form of quick visualisation helps to illustrate product opportunities as well as conceptual flaws at very early stages, as well as throughout the course of a project. Figure 3 shows this rapid form of communication using cardboard and other 'found' materials to illustrate how sensors on a toothbrush might measure blood oxygen, blood pressure and pulse, or how a shelf in a toilet could weigh and photograph faecal matter.

Figure 3: Illustrates initial early stage ideas in three... dimensional sketch models
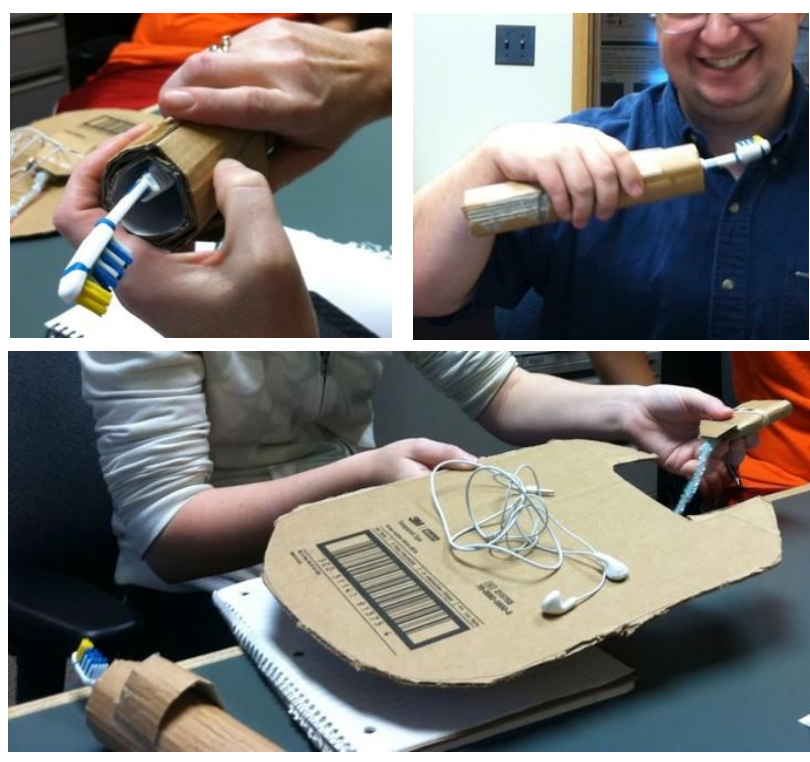

\section{Ergonomic crutch handle}

Yearlong independent study course --- industrial design undergraduate students

The project objective was to improve the experience and comfort of using crutches, thus increasing compliance during the healing process. Students used empathic modelling (experiencing with your own body the physical situations of others) (refer to Figure 4) to reveal the 
'white space' (unmet needs, opportunities for product improvement and innovation) left by currently marketed products.

Guided by design and engineering professionals, these students are focusing on simple and potentially patentable modifications to auxiliary parts to 'standard' crutches available in the USA to improve the user experience.

Figure 4: Students conducting empathic modelling in order to gain intimate insight and understanding into the experience of using a crutch.
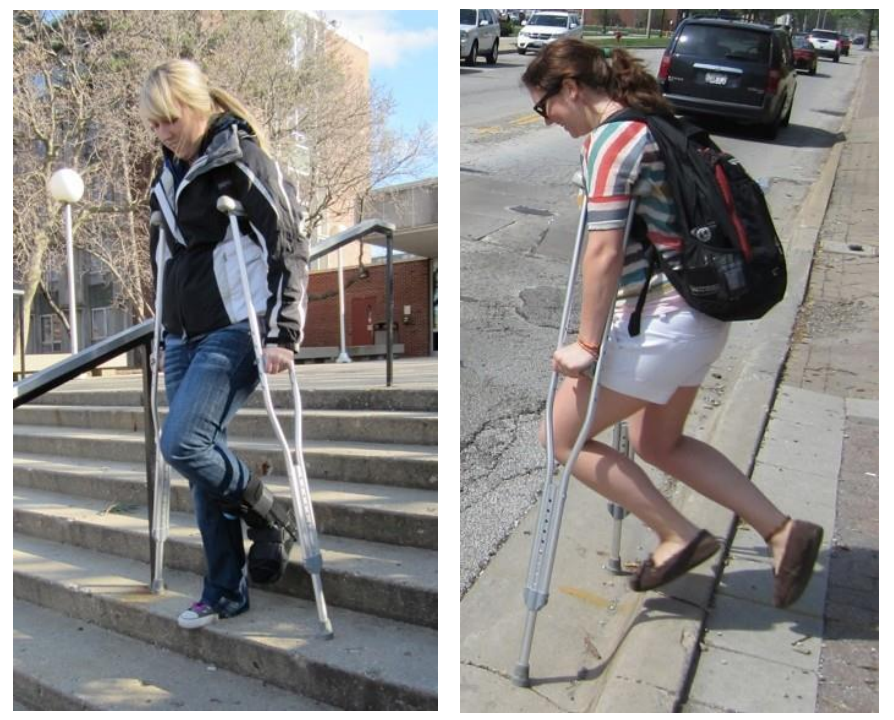

\section{Laser otoscope}

Multiyear research project --- industrial design graduate student in collaboration with bioengineering and engineering graduate students and advisers

Collaborating with a team of scientists and technologists, an industrial design graduate research assistant is responding to the needs of health care practitioners to gather highresolution data imaging in their office environments. The student has used ethnographic methods (recording how people interact with products, services and experiences) to observe authentic human experience (what people actually do as opposed to what they say or think they do). The photo in Figure 5 illustrates how one doctor holds an otoscope differently than how it was designed to be held (by the handle). Additionally, the doctor had to adjust his own height in relation to the patient to perform the test (a position that would not be sustainable for a longer period).
Figure 5: Ethnographic observation of authentic human behaviour: Clinician demonstrating how he uses otoscope.

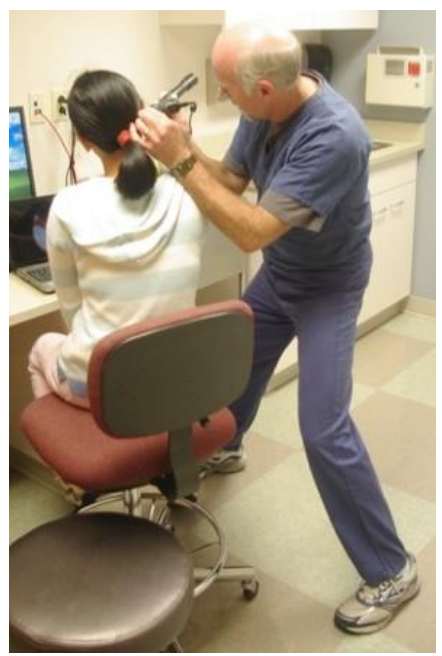

The engineers built a proof of concept model of a high-resolution data imaging laser otoscope in their laboratory from standard off-the--shelf parts. Their focus was on designing and proving the technology, whilst the designer's challenge was to translate and transform this model into a device that resonates with the final user considering human interaction and engagement (refer to Figure 6).

Figure 6: (a) Engineering proof of concept device, (b) ergonomic studies through rapid sketch modeling and (c) form visualisation.

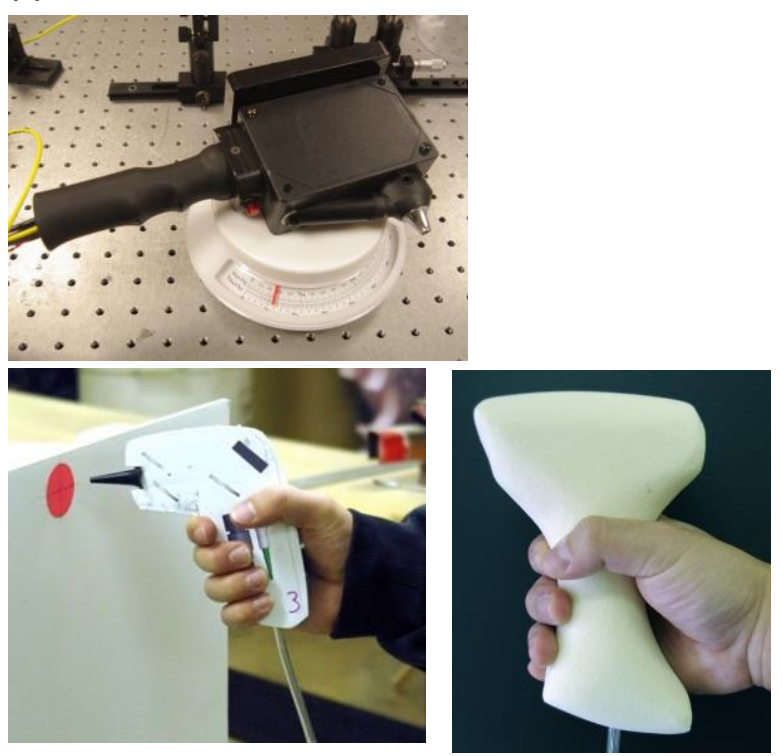

Industrial designers are immersed in considering the world of tomorrow --- how things 'could' be, taking highly technical devices (as in Figure 6) and imagining new approaches. Whilst the paradigm of a 'handle grip' for this type of device was 'expected', the designer explored other conceptual possibilities such wrapping it around the wrist of the health care provider (Figure 7). 
Figure 7: Concept exploration and visualisation sketch.

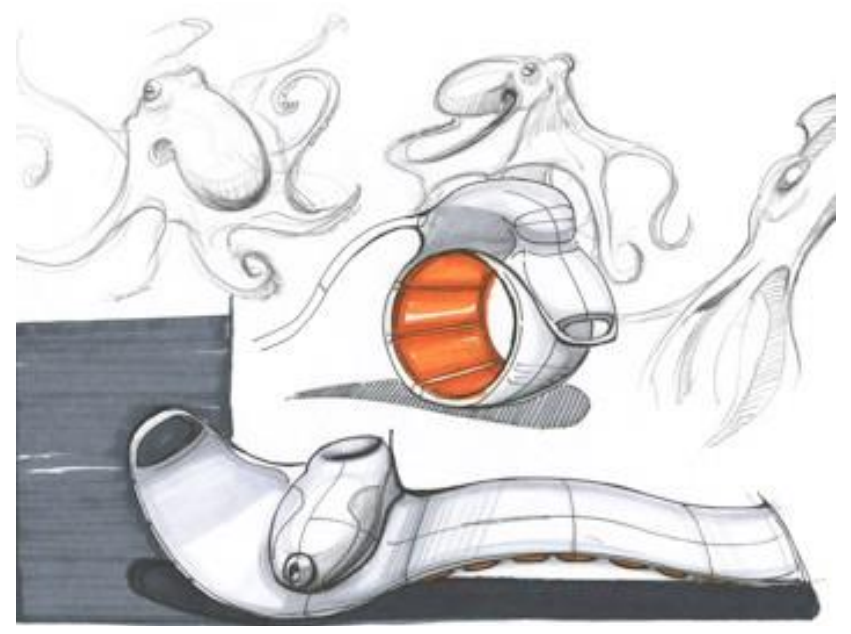

\section{Human-centred product design}

One semester course - industrial design, business, graphic design undergraduate students.

Student designers were guided to immerse themselves in the everyday life of real people focusing on the concepts of 'Aging in Place' (people having the opportunity to remain in their own home as their physical and/or cognitive abilities change over time) and 'Healthy Living' (maintaining your health through balanced diet, exercise, relaxation, and social and emotional connectedness) to discover problems and unmet needs, and then to seek solutions that will satisfy functional and emotional needs for the user. Figure 8 illustrates a mind mapping technique used to explore the concept of 'Aging in Place'. First, students explored what this means from their own perspectives as 20 year olds, and then followed this up by interviewing their parents $(40+$ years old). These activities were designed to demonstrate that one's personal perspective could likely be very different from the user group for which they are creating products. Developing an understanding that you as 'designer' are not the 'customer' exposes the importance of engaging with real users early on in the design and problem solving process.

Figure 8: Students created mind maps to illustrate 'Aging in Place' from their own perspectives (as 20 year olds).

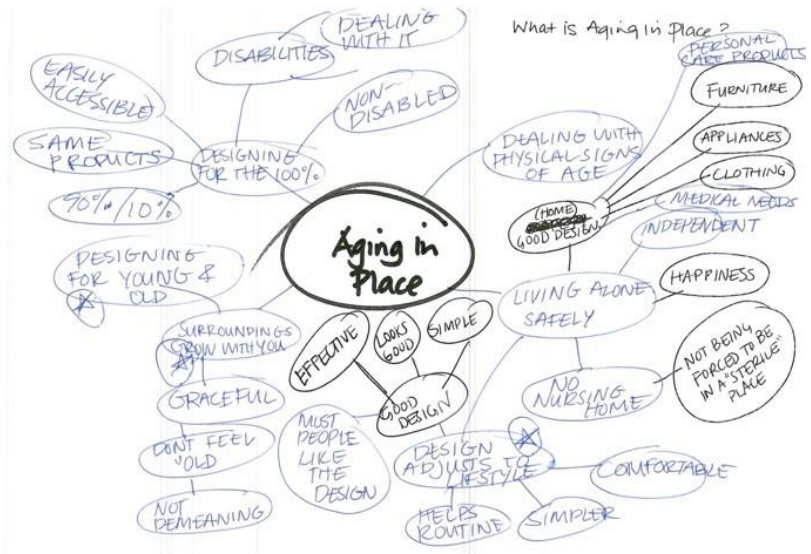

Using brainstorming techniques, students explored daily tasks of a range of various age groups. Employing empathic modeling techniques (e.g. homelessness, limited mobility, healthy eating), they identified key problems and potential solutions such as:

- Methods to help mid-life age people move heavy objects in their home.

- Bathroom accessories that have an assistive technology function (e.g. toilet paper holder that helps you lift yourself off the toilet).

- Walking stick inspired by the human foot.

- Means of motivating university students to eat healthier.

- Ways to encourage outdoor exercise (e.g. camping).

- Homelessness (refer to Figure 9).

One of the students used empathic modelling to experience 'homelessness' by spending 18 hours outside in cool and damp weather, without money, shelter, sustenance or a mobile phone. His discomfort was captured in Figure 9 as he attempted to dry himself in the sunshine after a rain shower. He reported that this simple exercise has had a strong and lasting emotional impact on him. Being disconnected from family and friends was disconcerting. Over the course of his modelling, his sense of dignity was being eroded as he recognised that people crossed the road to avoid him.

Figure 9: Design student warming in the sun as he used empathic modelling to explore what it was like to be homeless.

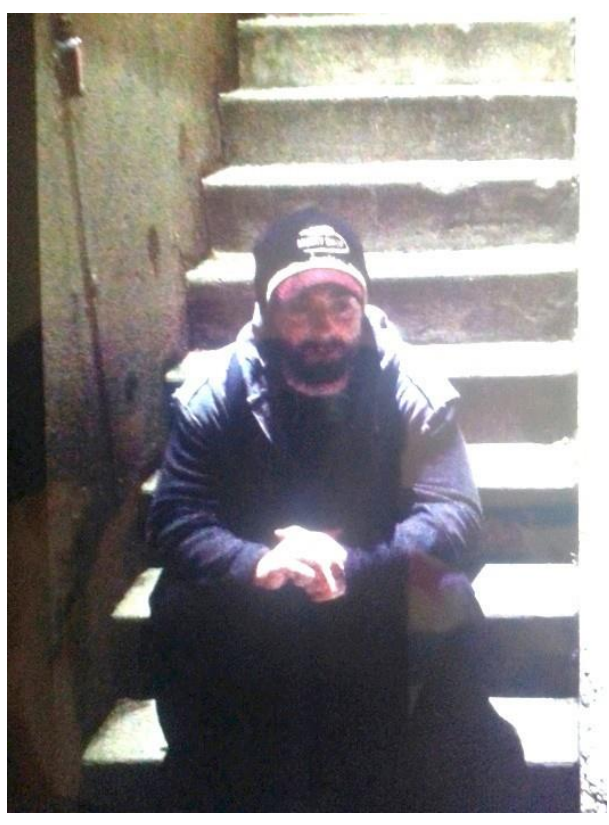




\section{The future is bright}

Emerging as a recognised field of professional practice in the early 1900s, industrial design was viewed for many years as the final step in product development --- a means to refine the appearance of the engineered product to reflect consumer tastes and trends.

The paradigm of design being a last stage in the product development process has shifted. In the late $20^{\text {th }}$ century, manufacturers and product developers recognised that collaboration between design, engineering, business, and marketing at the earliest, conceptual stages of development is critical to the success of new and existing initiatives. Uncovering connections between products, users and the environment is key to delivering products, interfaces, and services that satisfy user needs from both functional and emotional perspectives.

When tools from the designer's toolkit - user research, empathic modeling, comparative product research, sketching, model making, prototyping and usability testing are incorporated by the development team in iterative and generally non-linear pathways from the fuzzy front end to the final solution, the results are more robust, more intuitive, and meet the needs of real people.

The collection of projects discussed in this case study represents ways in which designers are building meaningful alliances with scientists, researchers, bio-engineers, medical informatics, and health care providers at an American University. This collaboration is developing a unique shared vision and language between diverse disciplines, and is advancing research while it enhances quality of life for individuals who will be impacted by the outcomes.

\section{References}

1. Bitterman N. Design of medical devices - a home perspective. Eur J Intern Med. 2011 Feb;22(1):39-.42.

2. Bates DW, Bitton A. The future of health information technology: in the patient-centred medical home. Health Aff (Millwood). 2010 Apr;29(4):614-21.

3. Kvedar JC, Nesbitt T, Kvedar JG, Darkins A. E--patient connectivity and the near team future. J Gen Intern Med. 2010; 26 (Suppl. 2): 636--638.

4. Liang BA, Mackey T. Quality and safety in medical care: what does the future hold? Arch Pathol Lab Med. 2011 Nov;135(11):1425-31

5. McGowen HH. Sensibilities, self-esteem \& shoes. New Mobility: Magazine for active wheelchair users (March). Available from:
http://www.newmobility.com/articleView.cfm?id=118 35\&srch=Multiple\%20Sclerosis $\quad$ (accessed 21 November 2011).

6. Kelly T, Littman J. The Ten Faces of Innovation. New York, NY. Doubleday; 2005

7. Visocky O'Grady J, Visocky O'Grady K. A Designer's Research Manual: Succeed in Design by Knowing Your Clients and What They Really Need. 1st ed. Beverly MA. Rockport; 2009

8. Hansen N, Philo C. The normality of doing things differently: bodies, spaces and disability geography. Tijdschrift voor Economische en Sociale Geografie. 2007; 98(4): 493--506.

9. Lutz BJ, Bowers BJ. Disability in everyday life. Qual Health Res. 2005 Oct;15(8):1037--54.

10. Clarkson J, Coleman R, Keates S, Lebbon C. Inclusive Design: Design for the whole population. London. Springer; 2003.

11. McDonagh D, Thomas J. (editorial) Design + empathy = intuitive design outcomes. The Design Journal. 2011; 14(3): 147--150.

12. McDonagh D, Thomas J, Strickfaden M. Empathic design research: towards a new mode of industrial design education. Design Principles \& Practices: An International Journal. 2011; 5(4): 301-314.

13. McDonagh D, Thomas J. Rethinking design thinking: empathy supporting innovation. Australas Med J 2010; 3(8): 458-464.

14. Laurel B. Design Research: Methods And Perspectives. Cambridge, MA. MIT Press; 2003

15. Koskinen I, Zimmerman J, Binder T, Redstrom J, Wensveen S. Design Practice Through Practice: From the Lab, Field and Showroom. Waltham, MA. Morgan Kaufmann; 2001

16. Pink D. A Whole New Mind: Why Right--Brainers Will Rule The Future. New York. Riverhead; 2006

\section{ACKNOWLEDGEMENTS}

We would like to thank the following colleagues and students who have helped make our research collaboration possible: Jennifer Amos, Stephen Boppart, Eric Chaney, Michelle Kwak, William Gavin, Frank Delgado, Matthew Entler, Christine Lekas, Ting Lu, Brian Ross, Lana Rottler, Bruce Schatz and Shuo (Janus) Yuan.

\section{PEER REVIEW}

Not commissioned. Externally peer reviewed. 


\section{CONFLICTS OF INTEREST}

[The authors declare that they have no competing interests.]

\section{FUNDING}

University of Illinois at Urbana-.Champaign, Office of Vice Chancellor for Research Interdisciplinary Innovation Initiative

National Institutes Of Health Grant

Number: 1R01EB013723--01

Principal Investigator: Stephen A Boppart, MD

Project Title: Partnership For Primary Care Imaging 